\title{
MOTHER EARTH DALAM NOVEL KERUMUNAN TERAKHIR KARYA OKKY MADASARI DAN NOVEL BLESS ME ULTIMA KARYA RUDOLFO ANAYA
}

\section{MOTHER EARTH IN THE NOVEL KERUMUNAN TERAKHIR WRITTEN BY OKKY MADASARI AND BLESS ME ULTIMA WRITTEN BY RUDOLFO ANAYA}

\author{
Adeline Grace Litaay ${ }^{1 *}$, Tri Pramesti ${ }^{2}$, Truli Suksas Yustia ${ }^{3}$, Mega Fadilla \\ Sastra Inggris, Universitas 17 Agustus 1945 Surabaya, Indonesia ${ }^{1,2,3,4}$ \\ gracelitaay07@gmail.com ${ }^{1}$, pramestimursidi@gmail.com ${ }^{2}$, $\underline{\text { truliesye@gmail.com }}^{3}$, \\ megafadilla22@gmail.com ${ }^{4}$ \\ *penulis korespondensi
}

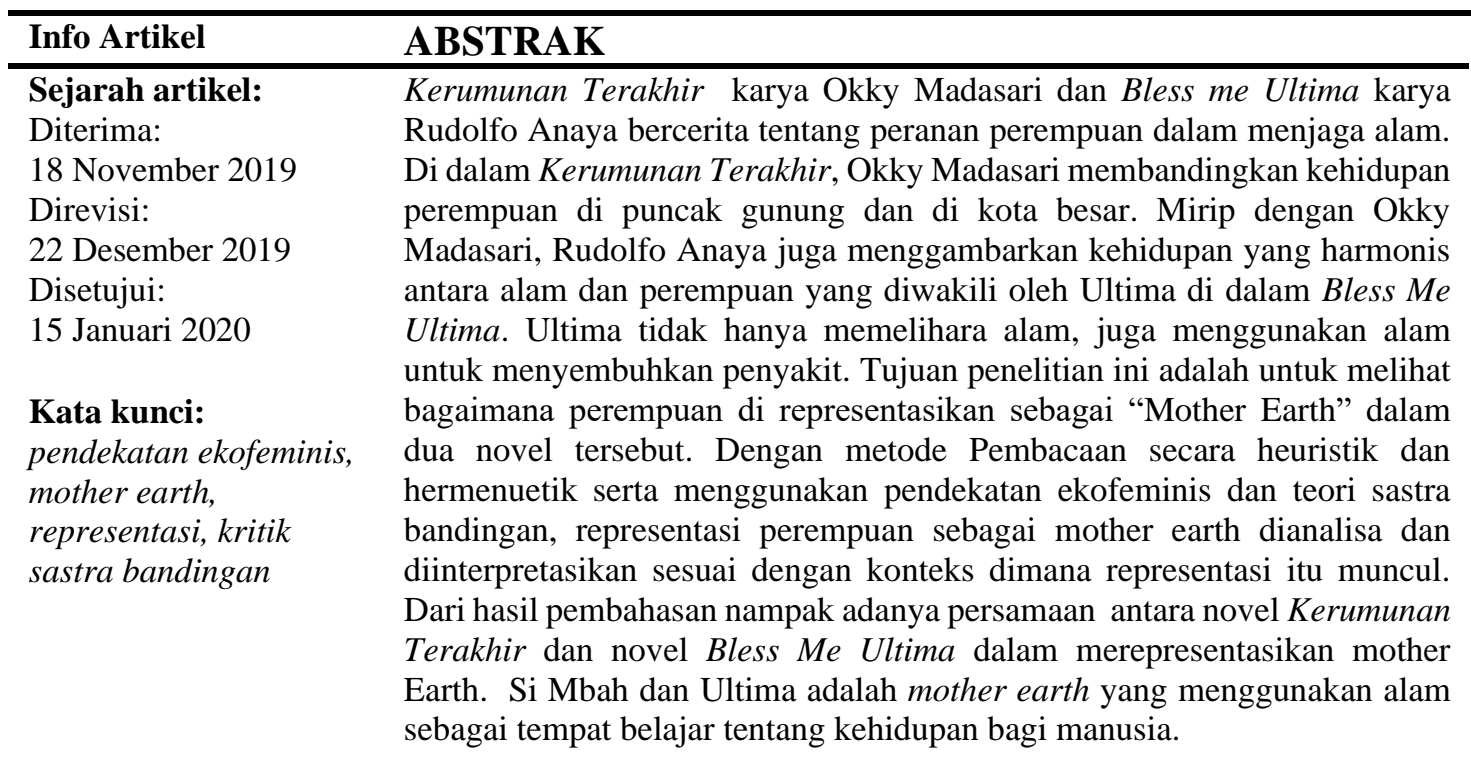

\begin{tabular}{|c|c|}
\hline Article Info & ABSTRACT \\
\hline $\begin{array}{l}\text { Article history: } \\
\text { Received: } \\
18 \text { November } 2019 \\
\text { Revised: } \\
22 \text { December } 2019 \\
\text { Accepted: } \\
15 \text { January } 2020 \\
\text { Keywords: } \\
\text { ecofeminism approach, } \\
\text { mother earth, } \\
\text { representation, } \\
\text { comparative literature }\end{array}$ & $\begin{array}{l}\text { Kerumunan Terakhir written by Okky Madasari and Bless me Ultima } \\
\text { written by Rudolfo Anaya tell the story of women in protecting nature. In } \\
\text { Kerumunan Terakhir Okky Madasari compares the lives of women at the } \\
\text { top of a mountain and in a big city. Similar to Okky Madasari, Rodolfo } \\
\text { Anaya also describes the harmonious life between nature and woman } \\
\text { represented by Ultima in Bless Me Ultima. Ultima does not only preserve } \\
\text { nature, she also uses nature to cure illness. Using the heuristic reading } \\
\text { method and applying the basic principles of ecofeminism about gender } \\
\text { equality and the close relationship between women and nature, this paper } \\
\text { tries to see how women are represented as mother earth in Indonesia and in } \\
\text { the United States contained in these two novels. By using an ecofeminism } \\
\text { approach and a comparative literary theory, the representation of women as } \\
\text { mother earth will be analyzed and interpreted according to the context in } \\
\text { which the representation appears. }\end{array}$ \\
\hline
\end{tabular}




\section{PENDAHULUAN}

Kerumunan Terakhir berkisah tentang kehidupan manusia di abad ke 21 ini. Manusia di masa ini mulai meninggalkan masa lalu menuju masa depan, dieksploitasi oleh teknologi dan materi, serta tak memberi kesempatan untuk diam, dan mengenang, berhenti, dan menoleh ke belakang. Sebaliknya kehidupan di desa terpencil yang ditokohkan oleh Mbah perempuan jauh dari modernitas. Meskipun demikian peran Mbah sebagai penjaga gunung yang jauh dari keramaian dan hingar bingar kota digambarkan lebih bahagia karena kedekatannya dengan alam.

Seperi Si Mbah yang berperan menjaga alam dan mengantarkan seorang anak laki laki menuju kedewasaan, Ultima dalam Bless Me Ultima Karya Rudolfo Anaya juga bercerita tentang seorang perempuan yang bertugas menjaga alam serta mengajari seorang anak laki laki menghargai alam dan menghormati perempuan. Ultima adalah seorang Curandera, orang yang menyembuhkan orang yang sakit dengan ramuan yang diambil dari alam. Ultima tinggal dengan keluarga Antonio Marez yang berusia enam tahun. Ultima tidak hanya numpang di rumah Antonio tetapi juga menjaga dan menemani Antonio melakukan perjalanan ke ambang kedewasaan. Ultima memberkahi Antonio dengan keberanian untuk menghadapi kemunafikan masa kanakkanak, keruntuhan moral saudaranya, dan mengajari bagaimana manusia seharusnya memperlakukan alam. Ultima selalu hadir dalam setiap fase kehidupan Antonio.

Hal tersebut di atas menjadi pertimbangan bahwa kandungan isi dalam dua novel tersebut banyak berbicara tentang hubungan perempuan dengan alam. Selain dari pada itu novel Kerumunan Terakhir dan novel Bless Me Ultima meskipun dari dua negara yang berbeda, mempunyai persamaan yaitu menggambarkan bumi sebagai perempuan atau "Mother Earth" yang merupakan sumber kebahagiaan dan kedamaian jiwa.

Mother Earth di dalam budaya Yunani-Romawi adalah personifikasi dari alam yang berfokus pada aspekaspek alam yang memberi kehidupan dan memelihara dengan mewujudkannya dalam bentuk Ibu. Istilah "Mother Earth" bisa dirujuk dari kata nature. Kata "nature" berasal dari kata Latin, "natura", yang berarti kelahiran. "Natura" dipersonifikasikan sebagai Mother Nature. Istilah ini digunakan sebagai sebuah konsep tentang tempat yaitu yang terletak di antara dewa dan manusia. Kata ini dapat dilacak dari Mitologi Yunani yang mengatakan bahwa "Earth" atau bumi dipersonifikasikan sebagai Dewi.

Dalam mitologi Inca, salah satu suku kuno di Amerika, Mama Pacha atau Pachamama adalah Dewi kesuburan yang memimpin penanaman dan panen. Pachamama dijumpai "beneath the clouds lives the EarthMother from whom is derived the Water of Life, who at her bosom feeds plants, animals and human" (Larousse 428). Di Indonesia istilah Mother Earth bisa diterjemahkan sebagai "Ibu Pertiwi" atau Dewi Sri sebagai "Rice Mother of the East Indies".

Hal ini dapat disimpulkan bahwa ada hubungan yang erat antara perempuan dan alam. Mother earth sangat penting dalam kehidupan hampir di setiap budaya di dunia karena ia yang mengharmonikan kehidupan manusia dalam hubungannya dengan alam. 
Dengan melihat representasi Mother Earth di dalam dua novel dari dua negara yang berbeda penelitian ini menggunakan pendekatan ekofeminis dan kajian sastra bandingan

Representasi berasal dari bahasa Latin repraesentare yang berarti "pameran," baik dalam bentuk perwakilan hukum atau dalam bentuk ekspresi artistik. Tindakan representasi harus dilakukan dengan mengganti atau bertindak atas nama sumber asli. Dengan kata lain representasi adalah proses pemaknaan kembali sebuah objek/fenomena/realitas yang maknanya akan tergantung bagaimana seseorang itu mengungkapkannya melalui bahasa.

Istilah ekofeminisme digunakan untuk menggambarkan pendekatan feminis dalam memahami ekologi. Pemikir ekofeminis memanfaatkan konsep gender yang mengkaji hubungan antara manusia dan alam. Menurut Carolyn Merchant di dalam artikelnya Ecofeminism, teori ekofeminisme menegaskan bahwa perspektif ekologi feminis tidak menempatkan perempuan pada posisi dominan dalam kekuasaan, melainkan menyerukan masyarakat egaliter di mana tidak ada satu kelompok dominan (hal. 193). Sedangkan menurut Carol Adams (2007) di dalam bukunya Ecofeminism and the Sacred Continuum mengatakan bahwa "Ecofeminism addresses the parallels between the oppression of nature and the oppression of women to emphasize the idea that both must be understood in order to properly recognize how they are connected. These parallels include but are not limited to seeing women and nature as property, seeing men as the curators of culture and women as the curators of nature, and how men dominate women and humans dominate nature" ( p. 2).

Ekofeminisme membahas kesejajaran antara penindasan alam dan penindasan perempuan untuk menekankan gagasan bahwa keduanya harus dipahami agar dapat mengenali dengan baik bagaimana mereka terhubung. Kesejajaran melihat tidak hanya perempuan dan alam sebagai benda tetapi juga melihat pria sebagai curator alam, dan bagaimana pria mendominasi wanita dan manusia mendominasi alam.

Kajian sastra bandingan adalah kajian bidang akademik yang berhubungan dengan kajian karya sastra dan ekspresi budaya melintasi batas-batas linguistik, nasional, dan disiplin. Kajian Sastra bandingan mempunyai peranan yang hampir sama dengan kajian hubungan internasional. Yang membedakan dengan kajian hubungan internasional adalah kajian sastra bandingan bekerja dengan bahasa dan tradisi artistik, sehingga dapat memahami budaya dari dalam.

Mempelajari karya sastra lintas budaya sama seperti mempelajari bentuk ekspresi yang bervariasi dari satu budaya ke budaya lainnya dan dari satu penulis ke penulis lainnya, karena setiap bangsa memiliki penyair dan lagu-lagunya, setiap benua memiliki novelis, penyair, dan penulis sejarahnya. Para kritikus sastra bandingan melihat di luar cakrawala sosial dan bahasa serta mempelajari karya sastra dari berbagai masyarakat dan era.

\section{METODE}

Penelitian ini merupakan
penelitian deskriptif kualitatif.
Metodologi penelitian kualitatif sesuai
untuk penelitian ini karena cocok untuk
mengungkap kompleksitas makna atau 
sifat pengalaman. Metodologi ini digunakan karena dapat memberikan pemahaman yang kaya akan kehidupan, pengalaman sastra, interaksi interpersonal, dan konteks sosial budaya yang kompleks. Penelitian ini menggunakan teks sastra untuk analisisnya. Data utama diambil terutama dari dua karya sastra yang terbit di Indonesia dan di Amerika Serikat. Karena sumber data adalah novel dan datanya adalah kutipan dalam novel, maka teknik untuk mengumpulkan data adalah dokumentasi. Langkah-langkah yang diperlukan adalah (1) membaca novel secara heuristic dan hermenutik, (2) inventarisasi kutipan dengan tujuan mendapatkan data-data yang berkaitan dengan rumusan masalah, dan klasifikasi data Setelah proses pengumpulan data, dilakukan proses analisis yang mana teknik yang digunakan adalah deskriptif interpretasi. Deskriptif adalah sifat tulisan analisis yang menguraikan segala detail dan informasi serta argumen dalam analisis dan interpretasi merujuk pada gaya analisis yang dilakukan dalam penelitian ini. Adapun langkah-langkah yang dilakukan adalah (1) meproposisikan masalah, (2) data dari sumber data sangat relevan dengan permasalahan yang diangkat, (3) analisis, dan (4) penarikan kesimpulan.

\section{HASIL DAN PEMBAHASAN}

\section{Si Mbah sebagai Mother Earth}

Si Mbah adalah salah satu karakter dalam Kerumunan Terakhir. Si Mbah digambarkan sebagai seorang wanita tua yang bekerja sebagai penjaga Suroloyo. Suroloyo adalah puncak gunung yang diyakini orang sebagai tempat suci. di tempat itu orang-orang datang dan berdoa untuk berkah. Pekerjaan Si Mbah sebagai penjaga gunung bukanlah pekerjaan yang lazim bagi perempuan. Pekerjaan sebagai pelindung tempat suci di puncak gunung adalah pekerjaan yang biasanya dilakukan oleh pria. Si Mbah telah bertugas sebagai wali Suroloyo selama lebih dari 45 tahun. Sejak suaminya memilih untuk menikah lagi, Si Mbah memutuskan untuk hidup menyendiri di puncak gunung untuk menyembuhkan luka hatinya karena pengkhianatan suaminya. Dia membesarkan putra satu-satunya sendirian dengan semua yang dia dapatkan di sekelilingnya dan kadangkadang uang yang dimiliki pengunjung Suroloyo untuknya (Madasari, 2016: 24). $\mathrm{Si}$ Mbah mendapatkan pekerjaannya sebagai penjaga Suroloyo sejak penjaga sebelumnya meninggal. Kematian penjaga membuat Si Mbah tidak bisa bertanya apalagi menyangkal pesan yang diterimanya. Pekerjaan utamanya adalah menjaga Suroloyo bersih dan suci.

Bekerja sebagai penjaga gunung bagi seorang perempuan adalah tugas yang berat tetapi mulia. Tidak ada perempuan yang bisa menjalaninya kecuali Si Mbah. Dia harus memastikan bahwa tidak ada yang merusak alam, setiap hari dia harus berjalan naik turun gunung untuk memastikan bahwa alam berfungsi sebagaimana mestinya. Dia harus naik ke atas untuk menyapu dan membersihkan sampah, ranting, atau daun kering.

Sebagai seorang wanita penjaga alam, Si Mbah memiliki filosofi bahwa hidup harus seperti alam selalu memberi, tidak terburu-buru, tidak menginginkan apa yang tidak mungkin dicapai.

"Wis, Le, Nduk. Urip sing apikapik. Ora usah kemrungsung. Ora usah neko-neko. Sing 
penting ati ayem, tentrem. sing penting slamet urip ning ndonya. "(Madasari, 2016: 355).

Bagi Si Mbah manusia harus menerima kehidupan sebagaimana adanya dan tidak khawatir tentang halhal yang tidak dapat dia kontrol atau ubah. Pelajaran kehidupan dapat ditemukan di tempat paling sederhana yaitu di alam.

Si Mbah percaya bahwa hidup ini tidak ada kekurangan sarana. Manusia harus menghargai apa yang dia dapatkan. Menurutnya hal terpenting dalam hidup adalah kebajikan kebaikan, kedermawanan, kebahagiaan dan niat baik. Bagi Si Mbah hidup itu singkat dan merupakan persinggahan karena semua manusia harus mati.

"Simbah sedhilut maneh mati, Le," (Madasari, 2016: 355)

Si Mbah tidak pernah percaya pada sekolah modern. Dia tidak peduli apakah anaknya bersekolah atau tidak. Dia hanya mengikuti perintah kepala desa untuk mengirim setiap anak ke sekolah dasar. Dia lebih di alam karena mengajarkannya untuk tidak hidup dalam kepura-puraan, hidup tanpa mengikuti tata krama dan aturan sosial. Dia setuju bahwa setiap orang benarbenar unik, baik dalam penampilan fisik maupun kepribadian. Untuk menjalani kehidupan yang paling bahagia, tersehat, dan terlengkap, manusia berutang alam kepada diri mereka sendiri untuk sepenuhnya mengeksplorasi siapa mereka, minat mereka, hasrat mereka, ketakutan mereka, kekuatan mereka, dan kelemahan mereka.
"Bau tembakau yang memenuhi seluruh tubuhnya telah membuat saya ketagihan. dia melepaskan saya dari semua aturan dan kewajiban untuk berpura-pura. Saya bisa menyambutnya dengan kata-kata "kowe" yang di telinga orang Jawa terdengar sangat kasar ketika berbicara dengan orang yang lebih tua". Jauh lebih kasar daripada mengatakan "kamu" yang juga sama-sama dilarang (Madasari, 2016: 21).

“... Ketidaktahuan Si Mbah tentang sekolah dan dunia luar membuatku tumbuh nyaman dalam duniaku” (Madasari, 2016: 21).

Kehidupan Si Mbah jauh dari modernitas. Ketika dia mengunjungi putra dan cucunya di kota, dia merasa bahwa kota dengan modernitasnya membuatnya merasa sempit karena terlalu padat "gawe sumpek," (Madasari, 2016:23). Kurangnya pengetahuan Si Mbah tentang sekolah dan dunia luar membuat cucunya tumbuh nyaman di dunianya. Si Mbah percaya bahwa alam akan menyediakan segala yang dibutuhkan manusia selama manusia ingin bekerja keras untuk mendapatkannya.

"Saya mulai menanam tembakau setelah dua minggu tinggal di rumah $\mathrm{Si}$ Mbah. Si Mbah mengajari saya. Dia juga memberi saya batang bibit untuk ditanam. Pada hari yang sama, Maera mulai menanam bunga matahari. Si Mbah juga menunjukkan kepadanya tempat terbaik sehingga ketika bungabunga mekar, mereka bisa 
menghadapi

matahari"

(Madasari, 2016: 353).

\section{Ultima sebagai Mother Earth}

Ultima adalah salah satu karakter utama dalam Bless Me Ultima. Dia digambarkan sebagai seorang Curandera, a woman who knew the herbs and remedies of the ancients, a miracle-worker who could heal the sick (Anaya, 1972:4). Dia tinggal sendirian di puncak bukit llano di mana dia mengumpulkan tumbuh-tumbuhan yang hanya bisa dipanen di bawah cahaya bulan purnama (Anaya, 1972:2). Selama musim panas dia diundang oleh keluarga Marez untuk tinggal bersama mereka. Keluarga ini memiliki seorang putra berusia enam tahun bernama Antonio. Ultima tidak hanya tinggal di rumah keluarga Antonio, tetapi dia juga mengajarkan Antonio bagaimana menghormati alam dan berurusan dengan kehidupan.

"She taught me the names of plants and flowers, of trees and bushes, of birds and animals; but most important. I learned from her that there was a beauty in the time of day and in the time of night, and that there was peace in the river and in the hills. She taught me to listen to the mystery of the groaning earth and to feel complete in the fulfillment of its time" (Anaya, 1972: 15).

Dia mengajarkan Antonio bagaimana menghargai semua tanaman dengan menamai mereka, belajar dari sungai yang mengalir. Pelangi adalah hal lain untuk dihargai dan dia meminta Antonio untuk mengingat bahwa semuanya indah dalam beberapa hal.

Bagi Ultima, manusia harus belajar dari alam karena semuanya disediakan oleh alam, makanan, air, obat-obatan, bahan untuk tempat tinggal, dan bahkan siklus alami seperti iklim dan nutrisi. Alam memberi manusia bebas biaya. Manusia diberkati bahwa alam Ibu memberi mereka kebutuhan sehari-hari akan makanan dan air dari alam. Manusia minum air dari hujan, danau, dan salju. Mereka memakan buah-buahan dan biji-bijian dari pohon, tanaman dari kebun kita dan binatang dari hutan.

"Ultima's soft hands would
carefully lift the plant and
examine it. She would take a
pinch and taste its quality. Then
she took the same pinch and put it
into a little black bag tied to a
sash around her waist. She told
me that the dry contents of the
bag contained a pinch of every
plant she had ever gathered since
she began her training as a
curandera many years ago"
(Anaya, 1972: 40).

Sebagai seseorang yang menghormati alam, Ultima memiliki filosofi bahwa "no road was too long for her to walk to its end" (Anaya, 1972:3). Seperti jalan yang panjang, manusia harus berjalan untuk mencapai tujuannya. Dalam mencapai tujuannya, manusia menghadapi beberapa kendala, badai, kesedihan, dan kegagalan. "Ultima said to take life's experiences and build strength from them, not weakness." (Anaya, 1972:261). Karena hidupnya bukan tentang kesempurnaan, hidup adalah tentang menerima ketidakbahagiaan dan hanya alam yang membuat manusia bahagia.

"I bless you in the name of all that is good and strong and beautiful, 
Antonio. Always have the strength to live. Love life, and if despair enters your heart, look for me in the evenings when the wind is gentle and the owls sing in the hills. I shall be with you"(Anaya, 1972:261).

Belajar dari alam adalah salah satu cara untuk membuat orang bahagia.

"from my father and Ultima I had learned that the greater immortality is in the freedom of man, and that freedom is best nourished by the noble expanse of land and air and pure, white sky. I dreaded to think of a time when I could not walk upon the llano and feel like the eagle that floats on its skies: free, immortal, limitless" (Anaya, 1972:228).

\section{Perempuan sebagai Representasi Mother Earth di dalam Kerumunan Terakhir dan Bless Me Ultima}

Baik novel Kerumunan

Terakhir Okky Madasari dan novel Bless Me Ultima, karya Rudolfo Anaya tidak hanya berbicara tentang hubungan antara perempuan dan alam, tetapi mereka juga bercerita tentang hubungan antara "Ibu" dan putraputranya. Matajaya adalah cucunya (putra dari putra) Si Mbah. Dia dipercayakan kepada neneknya karena ibunya, Matajaya kewalahan merawat dua anaknya yang lain. Hubungan Matajaya dan Si Mbah tidak hanya hubungan antara nenek dan cucu, tetapi Simbah juga bertindak sebagai mentornya. Si Mbah yang membawa Matajaya ke usia dewasa. Si Mbah mengajarkan Matajaya untuk selalu jujur pada dirinya sendiri.
"Si Mbah mengajari saya cara berpakaian sederhana, Si Mbah membuat saya tidak nyaman menggunakan semua jenis pakaian. Hanya kemeja tipis yang mulai usang yang lebih nyaman dipakai yang membuat saya merasa nyaman. Ibu, yang selalu mengajari saya cara berpakaian rapi, sekarang tidak bisa mengatur saya lagi. Dia membiarkan saya memakai pakaian yang saya sukai" (Madasari, 2016:36).

Ketika Matajaya dewasa dan harus bertanggung jawab dengan kehidupannya, Si Mbah juga mengajarinya untuk percaya bahwa alam akan memberikan semua yang dia butuhkan.

"Saya mulai menanam tembakau setelah dua minggu tinggal di rumah Si Mbah. Si Mbah mengajari saya. dia juga memberi saya batang bibit untuk ditanam. Pada hari yang sama, Maera mulai menanam bunga matahari. $\mathrm{Si}$ Mbah juga menunjukkan padanya tempat terbaik sehingga ketika bunga-bunga mekar mereka dapat menghadapi matahari (Madasari, 2016: 353).

Seperti Si Mbah dan Matajaya, hubungan antara Ultima dan Antonio sangat dekat.

"I had been close to Ultima since she came to stay with us, but I was never closer or more appreciative of her good than those weeks when I was sick and she cared for me. (Anaya, 1972: 189). 
Ibu Antonio ingin dia menjadi pendeta di komunitas petani, tempat keluarganya tinggal. Untuk menjadi seorang imam, Antonio harus berpisah dengan ibunya yang membuatnya sibuk dan cemas. Dengan belajar menjadi seorang imam, Antonio mulai mempertanyakan nasibnya, kehidupan dan kematiannya, kebaikan dan kejahatan.

Ultima yang datang untuk tinggal bersama keluarganya mengajarkan kepadanya bagaimana menerima takdirnya, menghadapi kesulitan dan bagaimana membangun hubungan dengan alam. Ultima mengajarnya dengan menceritakan kisah dan legenda leluhurnya. Kedekatan hubungan dengan Ultima membuat Antonio membuka pikirannya untuk memahami lingkungannya dan menerima takdirnya.

"The trickle of water in the river bed was quiet, not singing as in the summer. The afternoons were gray and quiet, charged with the air of ripeness and belonging. There was a safe, secure welcome in opening the kitchen door and being greeted by the warm aroma of cooking, and my mother and Ultima" (Anaya, 1972: 147).

Baik Si Mbah dan Ultima mengajarkan anak laki-laki untuk menjadi kuat, belajar seperti sungai yang mengalir sehingga ketika mereka dilanda badai (angin, hujan, petir) mereka akan mampu melewatinya serta mampu berdiri tegak. Pelajaran yang kedua yang mereka dapatkan adalah kesabaran. Ultima meminta Antonio untuk mengambil waktu berhenti dan melihat-lihat sekelilingnya. Dia mengajari bagaimana caranya untuk mencegah terjadinya kecelakaan dan hal hal yang lain yang bisa dia dapatkan dari kehidupan. Selain itu Matajaya dan Antonio belajar bagaimana memberi rasa hormat. Si Mbah dan Ultima mengajari mereka cara menghormati alam. Mereka juga belajar bagaimana menerima yang artinya adalah bahwa segala sesuatu terjadi karena suatu alasan. Memahami pentingnya siklus hidup dan mati dan menerima bahwa segala sesuatu wajar terjadi. Penyakit, cedera, atau kecelakaan terjadi dan manusia tidak selalu dapat mengendalikan hasilnya. Seorang ibu dapat mengasuh alam. Ibu sering mengambil kendali dan memutuskan jalan yang harus dilalui. Mother Earth mengajarkan untuk menghargai hal-hal yang sederhana seperti: udara segar, keindahan alam, badan air, hujan, burung, dan banyak lagi. Sebagai Mother Earth, Si Mbah dan Ultima mengajarkan kepada anak laki-laki muda bahwa makhluk hidup memiliki peran unik mereka sendiri dalam ekosistem. Manusia memiliki bakat unik mereka sendiri, dan peran yang mereka mainkan dalam masyarakat. Nilai seseorang tidak berkurang berdasarkan ketidakmampuan orang lain untuk melihat nilai seseorang.

\section{PENUTUP}

Kerumunan Terakhir dan Bless Me Ultima adalah novel yang berbicara tentang hubungan perempuan/ibu dan alam. Perempuan dan Ibu adalah salah satu indikasi pertama dari kedaulatan Allah dalam hidup kita. Ibu mengajar anak-anaknya untuk memiliki kepercayaan diri dan kepercayaan pada diri kita sendiri. Dari pengalaman seorang Ibu, dia tahu betapa pentingnya bagi seorang anak untuk percaya pada diri mereka sendiri agar 
mereka kelak menjadi anak yang utuh, kuat dan tumbuh dengan estimasi yang sehat tentang diri sendiri. Meskipun Si Mbah tidak melahirkan Matajaya dan Ultima juga tidak melhirkan Antonio, keduanya memiliki hubungan seperti Ibu dan anak. Hubungan mereka memiliki dampak yang penting terhadap kedewasaan mereka. Kedekatan Si Mbah dan Ultima dengan alam dan bagaimana mereka menggunakan alam sebagai sarana belajar, dapat dikatakan bahwa mereka adalah Mother Earth. Melalui alam, mereka mengajar anak laki-laki muda untuk memiliki Kekuatan, kesabaran, rasa hormat, menerima, dan memiliki harga diri.

\section{DAFTAR PUSTAKA}

Adams, Carol .2007. Ecofeminism and the Sacred. Continuum. pp. 1-8.

Anaya, Rudolfo.1999. Bless Me Ultima. Grand Central Publishing USA
Gaard, Greta and Gruen, Lori. 1993. Ecofeminism: Toward Global Justice and Planetary Health in Society and Nature 2 p.1 -35

Glotfelty, Cheryll and Fromm, Harold (editor) 1996. The Ecocriticism Reader Landmarks in Literary Ecology. University of Georgia Press

Leeming, David Adams (2010). Creation Myths of the World: An Encyclopedia. 1 (2 (revised, illustrated) ed.). ABCCLIO. p. 118. ISBN 978-159884-174-9

Madasari, Okky. 2016. Kerumunan Terakhir. Gramedia. Jakarta

Merchant, Carolyn (2005). "Ecofeminism". Radical Ecology. Routledge. pp. 193221. 